\title{
Linking people and activities through community mobility: an international comparison of the mobility patterns of older drivers and non-drivers
}

\author{
Carolyn Unsworth ${ }^{1,2 *}$ (D), Anne Dickerson ${ }^{3}$, Isabelle Gélinas ${ }^{4}$, Priscilla Harries ${ }^{5,6}$, \\ Isabel Margot-Cattin ${ }^{7,8}$, Barbara Mazer ${ }^{4}$, Tadhg Stapleton ${ }^{9}$, Lizette Swanepoel ${ }^{10}$, \\ Amanda Timmer ${ }^{11}$, Lana Van Niekerk ${ }^{10}$ and Brenda Vrkljan ${ }^{12}$ \\ ${ }^{1}$ Federation University, Churchill, Victoria, Australia, ${ }^{2}$ Monash University, Melbourne, Australia, ${ }^{3}$ East \\ Carolina University, Greenville, North Carolina, USA, ${ }^{4}$ McGill University, Montreal, Canada, ${ }^{5}$ Centre for \\ Applied Health and Social Care Research, Kingston University and St George's University of London, \\ London, UK, ${ }^{6}$ Brunel University London, UK, ${ }^{7}$ University of Applied Sciences and Arts of Western \\ Switzerland (HES-SO), Lausanne, Switzerland, ${ }^{8}$ Karolinska Institute, Stockholm, Sweden, ${ }^{9}$ Trinity College \\ Dublin, Dublin, Ireland, ${ }^{10}$ Stellenbosch University, Parow, South Africa, ${ }^{11}$ Ramsay Health Care, Donvale \\ Rehabilitation Hospital, Melbourne, Australia and ${ }^{12}$ McMaster University, Hamilton, Ontario, Canada \\ ${ }^{*}$ Corresponding author. Email: c.unsworth@federation.edu.au
}

(Accepted 3 December 2020; first published online 30 March 2021)

\begin{abstract}
Community mobility using private and public transportation is important for maintaining health, social participation and living well in later life. This international cross-sectional cohort study $(\mathrm{N}=246)$ reported on the health and driving status of older adults from seven countries where the mobility patterns of drivers and non-drivers were compared in terms of city and rural areas, weather, as well as their respective differences in the number of out-of-home places accessed and quality of life. Older adults participated in a semi-structured interview and completed four standardised instruments: the EQ-5D-5L, modified PULSES health profile, modified Transportation Questionnaire, and the Transport - Participation in Activities and Places Outside the Home. Results suggested inclement weather and place of residence negatively impacted out-of-home activities but did not increase use of public transportation. Drivers accessed more out-of-home activities than non-drivers, suggesting higher community participation among this group, and quality of life was generally high among all participants, but slightly higher for drivers. Findings indicate that a complex myriad of factors can influence community mobility in older adults and further investigations are needed to understand patterns of transport in later life, particularly with regard to those factors that promote and maintain transport mobility, and relationships between transport mobility, community participation and quality of life.
\end{abstract}


Keywords: older adults; transportation mobility; community activities; participation; automobile driving

\section{Introduction}

As our global population ages, both the number and percentage of people aged 65 years and older continues to rise (Organisation for Economic Co-operation and Development, 2011; Centers for Disease Control and Prevention and National Center for Health Statistics, 2018). Research on factors that can support older adults' engagement in meaningful social and community activities, at valued destinations, is critically needed. For the purposes of this paper, meaningful activities are defined as those of significance to the individual, and valued destinations are defined as places that are highly regarded and important (Christiansen and Townsend, 2014; Taylor 2017). Having a driver's licence is one factor that has been linked to both identity and autonomy in older adulthood (Vrkljan and Polgar, 2007). As many daily occupations, or meaningful activities, occur across a broad spectrum of geographical locations, older adults need community mobility strategies in place to ensure continued access to these activities, which can promote wellness in later life (Dickerson et al., 2019; O'Neill et al., 2019). While transportation access is vital, O'Neill et al. (2019) assert this social determinant of health is one of the most neglected in both research and policy. Multiple studies demonstrate the strong relationship between community mobility in older adulthood in terms of physical and psychological health, engaging in social activities and quality of life (Metz, 2000; Yeom et al., 2008; Choi et al., 2014; Zeitler and Buys, 2015). Many countries have taken active steps to improve community mobility options for older adults such as low or no fares for public transport, dial-a-ride rural bus services and ensuring a combination of travel options are readily available (Lynott et al., 2009; Tuller et al., 2010; Krishnasamy et al., 2011; Hagan, 2020). Across this paper, we investigate community mobility in its broadest sense, encompassing transportation by private (car) or public methods (taxi, bus, rail), as well as by walking, and, as such, the terms community mobility and transportation mobility are used interchangeably.

Promoting community mobility is essential to supporting ageing in place. The concept of ageing in place (Golant and LaGreca, 1994; Sixsmith and Sixsmith, 2008; Martin et al., 2019; Ahn et al., 2020) has garnered international attention over the past three decades not only because of economic pragmatics, but because it supports people to remain in environments with established proximity to services and social networks, including family and friends. Active ageing enables older adults to continue to live meaningful and fulfilling lives, and contribute positively to society, which has been linked to health and human service savings (World Health Organization, 2015). Papageorgiou et al. (2016) explored facilitators and barriers to community participation among older adults and found the desire to maintain or even create new social relationships had a strong influence on community participation. Routines and habits individuals established earlier in life motivated them to maintain engagement in activities as they aged, while a desire to develop new interests also facilitated involvement in the community. However, transportation plays a critical role when it comes to enabling older adults to get to these activities and maintain their community involvement. Chao (2018) 
described transport planning as one of the pillars of urban planning and further identified public transport and facilitation of private vehicle use in later life as the two key components that enable older adults to remain connected in their communities and to age in their place of choice.

Vrkljan et al. (2011) and Wiles et al. (2012) both reported that ageing in place was linked to one's sense of identity in terms of their independence and autonomy, and that transportation accessibility, availability and affordability, particularly public transportation, was an enabler for ageing in place. Similarly, Gardner's (2014) ethnographic study found a complex array of factors can influence community mobility in later life. From this study, key motivators for maintaining community mobility included the preservation of identity and the need for social interaction, and as such, individually tailored solutions are often required to maintain out-of-home mobility. Hagan (2020) even argued that a rural dial-a-ride bus service was itself a place for informal socialising, coming in as a third place and following 'home' and 'shopping/dutiful visits/appointment'. This accessible form of transport was found to support ageing in one's local community, as older adults could both socialise as well as receive valued transport to address isolation. Conversely, several factors have been identified as negatively associated with community mobility, including traffic congestion and lack of available seating on public transport (Krishnasamy et al., 2013), recent hospitalisation (Loyd et al., 2018), weather (Smith et al., 2016), gender (Fristedt et al., 2014; Choi et al., 2015) and urban versus rural living (Mattson, 2011). When referring to weather, this paper uses the terms 'good' and 'inclement' where the latter encompasses both extreme heat as well as extreme cold, rainy, icy and/or snowy conditions.

Driving is also crucial for many people to age in place, as it is often the most convenient option for personal transportation and supports community participation. Zeitler and Buys (2015) used GPS and in-depth interviews to track the community mobility of 13 people living in city and suburban environments in Australia-areas not well-served by public transport. Key findings suggested older adults needed to reach a variety of destinations across the city to engage in their daily occupations and preferred the flexibility car travel offered; that driving supported other older adults in the same social circle; and that a significant advantage of car travel was the ability to transport both goods and other people. Much research has focused on medically at-risk older drivers, where driving assessment, driving cessation and transitions to non-driving have been investigated (Choi et al., 2012; Liddle et al., 2012; Unsworth et al., 2012; Rapoport et al., 2013; Stapleton et al., 2015; Dickerson et al., 2019). Findings in this area highlight that it is not age per se that may impact continued driving, rather it is the impact of medical conditions and other functional declines that can affect sensory, cognitive and physical abilities needed for safe driving (Levasseur et al., 2015; Mazer et al., 2016). Most older adults prefer to retain their ability to drive for as long as possible and their personal automobile remains their primary mode of transport (Turcotte, 2012; Zeitler and Buys, 2015; Mazer et al., 2016). As such, many older drivers use selfregulatory strategies, including adjusting where and when they get behind-the-wheel, making fewer and shorter trips in peak traffic, at dusk and at night, and not driving during inclement weather (Unsworth et al., 2007; Rapoport et al., 2013; Levasseur et al., 2015; Koppel et al., 2016; O’Neill et al., 
2019). Not driving in inclement weather is of particular interest, as there are few studies that have examined if older adults replace driving with other forms of transport due to more challenging weather conditions, or simply do not go out at all. In addition, some of these self-regulation strategies are matched by progressive legislation in certain jurisdictions that allows for temporal and geographically restricted driving options as a method of enabling continued, albeit restricted, driving for as long as possible (Austroads and National Transport Commission, 2016; Road Safety Authority, 2019). Nevertheless, driving cessation is inevitable, with research suggesting that men will have approximately six years and women will have an average of ten years of dependency on alternative modes of transportation beyond their personal automobile (Foley et al., 2002). Hence, access to and utilisation of public transportation among older adults requires investigation. Older adults who have never driven or who need to stop driving may need to rely on public transport systems, friends and family, or other modes to enable continued social connectedness and being able to age in place in their local communities. These alternative transport options should be safe, affordable and accessible.

Given the ageing of populations globally, research is critically needed to examine how support for transportation options in older adulthood can impact community participation. This study stems from an international collaboration (Vaucher et al., 2017) investigating the broad relationship between community transportation mobility, out-of-home participation and living well among older adults. The research in this paper examined the mobility patterns of older adults in different countries and differences in out-of-home activities and quality of life between older adults who are still driving and those who are no longer driving or never drove. Specifically, the aims of this research examined (a) demographic factors such as age and gender, health status and driving status among older adults from seven countries, (b) the impact of age, gender, weather, time of day, road type, traffic volume and city versus rural location on driving patterns of older drivers, and avoidance of any particular driving conditions, (c) the types of transportation used by older drivers and non-drivers to access out-of-home places and any differences between these groups in terms of the places accessed, and (d) if there are any differences between drivers and non-drivers on measures of quality of life and satisfaction with life.

\section{Methods}

\section{Study design}

The study has a cross-sectional cohort design using data collected in seven countries: Australia, Canada, United Kingdom (UK), Ireland, South Africa, Switzerland and the United States of America (USA). The research was conducted according to the World Medical Association Declaration of Helsinki. The lead institution which reviewed the ethics proposal was Brunel University London. Each researcher obtained ethical approval from their academic institution to conduct the study and a data transfer agreement was signed and approved by the ethics committees.

\section{Participants}

To participate in the study, individuals were aged 65 years or older, community dwelling (not living in a residential aged-care facility) and able to speak the native 
language of the interviewers or translator in countries where available. Convenience sampling was used to recruit participants via flyers placed at community facilities, through general medical practitioners and from participants from other research projects who indicated they were agreeable to be contacted about future studies. Interested individuals who met these criteria contacted the local research team and were provided with written information about the study. Those who agreed to participate were asked to sign a written consent form or provide informed verbal consent at the start of the interview.

\section{Measures}

A semi-structured interview and four standardised measures were administered in this research. The semi-structured interview recorded the participant's responses to a standard sequence of questions that gathered information such as age, gender, living environment, work status, mobility aid status and current driving status. No personally identifying data were gathered. The EQ-5D-5L (Herdman et al., 2011), modified PULSES health profile (Granger et al., 1979), modified Transportation Questionnaire (Dahan-Oliel et al., 2010) and modified Participation in Activities and Places Outside the Home (ACT-OUT) (Margot-Cattin et al., 2019) were all administered.

The EQ-5D-5L is a patient-reported outcome measure of health-related quality of life comprising five dimensions, including mobility, self-care, usual activities, pain/discomfort and anxiety/depression. Each dimension is evaluated on a fivelevel response scale (level $1=$ no problem to level $5=$ extreme problem). It also includes a visual analogue scale recording the participants' current overall healthrelated quality of life, with 100 representing the best health state while 0 represents the worst.

The modified PULSES profile records functional ability across six categories: physical condition (P), upper limb function (U), lower limb function (L), sensory components (S), excretory functions (E) and support factors (S), and is scored from 1 to 4 with 1 representing the best function and 4 the least. These categories can be summed to obtain an overall score from 6 to 24 that reflects overall functional ability.

The Transportation Questionnaire measures frequency of use and satisfaction for different transport modalities, including driving, public transport (bus, train), taxi and walking. This measure was modified with the authors' permission to include the frequency of transportation modalities used in both good and inclement weather.

With the permission of the authors, we administered a modified version of the Participation in Activities and Places Outside the Home (ACT-OUT) (Margot-Cattin et al., 2019). The transportation components of the original ACT-OUT were relevant to the aims of this study and the originators subsequently asked that this modified version of ACT-OUT be renamed as TransportParticipation in Activities and Places Outside the Home (T-ACT-OUT). The T-ACT-OUT consisted of partial use of two of the three parts of the original ACT-OUT that were relevant to the current study. The T-ACT-OUT identifies 21 places that individuals typically visit, the frequency of participation and the transportation method people use to visit these places. Places are divided into 
four clusters: (1) administrative and self-care places (e.g. grocery store, hairdresser, bank, post office); (2) places for medical care (e.g. hospital, dentist, day care); (3) social, cultural and spiritual places (e.g. restaurant or cafe, cemetery, entertainment or cultural places); and (4) places for recreational and physical activities (e.g. garden; forest, mountain, lake or seaside; sports facility). Brief questions are also asked in relation to life satisfaction, as well as concerns and perceived risks related to being out in the community.

\section{Procedure}

A meeting with each participant was arranged during which the semi-structured interview and standardised questionnaires were administered, taking approximately 60 minutes to complete. The meetings were completed by trained interviewers either face to face or via telephone, depending on the preference of the individual participant. A standard proforma was used where the interviewer recorded the participant's responses to both interview questions and standardised assessments.

\section{Statistical analysis}

All anonymised data were analysed using IBM SPSS Statistics version 26. Data were checked for normality and adherence to statistical assumptions. For the first aim, demographic data and information from the standardised measures (EQ-5D-5L, Transportation Questionnaire, PULSES and T-ACT-OUT) were summarised using descriptive statistics (means, standard deviations, frequencies and percentages). Differences between participants across countries were analysed using analyses of variance for variables with continuous data (e.g. age and years since stopped work) and chi-square tests for variables with categorical data (e.g. gender and living environment). In relation to the second aim, the impact of weather, time of day, road type and traffic volume, and city versus rural location on driving patterns of older drivers were reported descriptively. Using chi-squared analyses, we then investigated any differences in the frequency that drivers used each type of transport between rural and city drivers in good weather, between rural and city drivers during inclement weather, and the difference between all drivers, in both good and inclement weather. Differences between city and rural drivers were also investigated for level of avoidance of a range of driving situations (e.g. night driving) also using chi-square tests. To investigate if gender had an impact on avoidance of certain driving situations, a chi-square test was undertaken, and this statistical test was similarly used to investigate differences between participants in three different age groups ( $\leqslant 73,74-80$ and $\geqslant 81$ years). For the third aim, the types of transportation used by older drivers and non-drivers to access out-of-home places as collected on the T-ACT-OUT were presented descriptively, and differences between attendance at these places for drivers and non-drivers were investigated using chisquare tests. For the final aim, differences between drivers and non-drivers in terms of health-related quality of life on the EQ-5D-5L Visual Analogie Scale was investigated using a Student's $t$-test, and satisfaction with life on the T-ACT-OUT was investigated using a chi-square test. 


\section{Results}

\section{Characteristics of participants including age, gender, health status and driving status}

Data were collected over an 18-month period between March 2018 and September 2019 with a total of 246 participants. To fulfil the first aim, Table 1 describes participant demographics. Most participants had completed tertiary education (67.9\%). The mean age ranged across countries from 73.7 years (standard deviation $(\mathrm{SD})=7.26)$ in Australia to $80.55(\mathrm{SD}=6.33)$ years in South Africa and, given this age profile, most participants were not working $(89.8 \%)$ at the time of data collection. A little more than half of the participants lived in a city/urban centre $(58.1 \%)$. Overall, participants had a mean score of $77.94(\mathrm{SD}=15.50)$ out of 100 on the EQ-5D-5L (with higher scores indicating better health-related quality of life). Generally, participants required no assistance with walking (76.7\%) and reported an average health profile of $8.08(\mathrm{SD}=2.09)$ out of 24 where lower scores indicate better health. As outlined in Table 1, demographics differed in several areas across countries, except gender, years since stopped work and use of a walking aid. While there were more females than males in the sample (65.4\% versus $34.6 \%)$, the difference between genders for each country was not statistically significantly different $(p=0.670)$. Most participants indicated they were still driving $(82.1 \%)$ with few having stopped driving (12.2\%) and very few reporting they had never driven (5.7\%).

\section{Impact of age, gender, weather and city versus rural living situation on driving patterns of older drivers}

Using a car, as a driver or passenger, or walking were the most frequently reported modes of transportation used by drivers. Table 2 indicates the modes of transportation and frequency of use in good and inclement weather, for both rural and city dwellers. Chi-square analyses revealed no differences between rural and city dwellers in good weather in terms of frequency of driving $(p=0.350)$, nor travelling as a passenger $(p=0.281)$, nor walking $(p=0.793)$. Similarly, no differences were found in the frequency of using these modes of transport during inclement weather: driving $(p=0.881)$, travelling as a passenger $(p=0.618)$ and walking $(p=0.290)$. However, when investigating differences in the frequency with which types of transport were used between all drivers (city and rural) in good and inclement weather, it was found that participants drove less frequently $(p=0.001)$ and walked less frequently $(p=0.001)$ during inclement weather. However, they had similar patterns of frequency for being a passenger in a car $(p=0.516)$, and although the sample sizes were too small for analysis, visual inspection of the data also suggests similar patterns of frequency for use of public transport, across good and inclement weather (see Table 2). Most rural and city participants reported they never used public transport options (e.g. bus, train or tram), regardless of the weather conditions, perhaps reflective of the high reliance on use of the personal car among participants.

Table 3 outlines the frequency with which drivers avoided certain conditions over the last three months. Drivers were more likely to report avoiding driving at night $(28.2 \%)$ and driving in inclement weather $(25 \%)$ than under all other conditions. Chi-square analyses investigated if there were any differences between avoiding a range of driving conditions and issues for city versus rural drivers, but none were 
Table 1. Characteristics of participants by country

\begin{tabular}{|c|c|c|c|c|c|c|c|c|c|}
\hline Characteristic & Total & Australia & Canada & UK & Ireland & South Africa & Switzerland & USA & $p^{1}$ \\
\hline $\mathrm{N}$ & 246 & 40 & 44 & 19 & 40 & 40 & 20 & 43 & \\
\hline Mean age (SD) & $76.75(7.35)$ & $73.70(7.26)$ & $80.27(6.97)$ & $76.65(10.22)$ & $74.30(5.76)$ & $80.55(6.33)$ & $77.65(5.23)$ & $74.35(6.76)$ & $<0.001$ \\
\hline \multicolumn{10}{|l|}{ Gender (N, \%): } \\
\hline Male & $85(34.6)$ & $13(32.5)$ & $20(45.5)$ & $5(26.3)$ & $13(32.5)$ & $13(32.5)$ & $5(25.0)$ & $16(37.2)$ & 0.670 \\
\hline Female & $161(65.4)$ & $27(67.5)$ & $24(54.5)$ & $14(73.7)$ & $27(67.5)$ & $27(67.5)$ & $15(75.0)$ & $27(62.8)$ & \\
\hline \multicolumn{10}{|l|}{$\begin{array}{l}\text { Living environment ( } \mathrm{N} \text {, } \\
\% \text { ): }\end{array}$} \\
\hline Rural & $103(41.9)$ & $17(42.5)$ & $6(13.6)$ & $18(94.7)$ & $27(67.5)$ & 0 & $6(30.0)$ & $29(67.4)$ & $<0.001$ \\
\hline City & $143(58.1)$ & $23(57.5)$ & $38(86.4)$ & $1(5.3)$ & $13(32.5)$ & $40(100.0)$ & $14(70.0)$ & $14(32.6)$ & \\
\hline \multicolumn{10}{|l|}{ Work status (N, \%): } \\
\hline Working & $25(10.2)$ & $8(20.0)$ & $4(9.1)$ & $3(15.8)$ & $1(2.5)$ & 0 & 0 & $5(12.0)$ & 0.003 \\
\hline Not working & $220(89.8)$ & $32(80.0)$ & $40(90.0)$ & $16(84.2)$ & $39(97.5)$ & $40(100.0)$ & $20(100.0)$ & $37(88.0)$ & \\
\hline $\begin{array}{l}\text { Mean years since } \\
\text { stopped work (SD) }\end{array}$ & $16.06(11.34)$ & $18.13(13.62)$ & 17.77 (11.09) & $13.27(8.91)$ & $14.26(10.10)$ & $12.77(9.14)$ & $15.79(7.67)$ & $16.81(13.38)$ & 0.547 \\
\hline \multicolumn{10}{|l|}{ Education $(\mathrm{N}, \%)$ : } \\
\hline No tertiary education & $78(32.1)$ & $16(40.0)$ & $9(20.5)$ & $5(27.8)$ & $31(77.5)$ & $8(20.0)$ & $1(5.6)$ & $8(18.6)$ & \\
\hline Tertiary educated & $165(67.9)$ & $24(60.0)$ & $35(79.5)$ & $13(72.2)$ & $9(22.5)$ & $32(80.0)$ & $17(94.4)$ & $35(81.4)$ & $<0.001$ \\
\hline $\begin{array}{l}\text { Mean quality of life } \\
\text { EQ-5D-5L-VAS (SD) }\end{array}$ & $77.94(15.50)$ & $77.65(16.30)$ & $83.86(9.82)$ & $77.22(13.31)$ & $70.00(15.70)$ & $79.35(14.87)$ & $77.25(17.88)$ & $78.84(17.35)$ & 0.008 \\
\hline $\begin{array}{l}\text { Mean PULSES health } \\
\text { profile (SD) }\end{array}$ & $8.08(2.09)$ & $7.75(1.80)$ & $7.07(1.33)$ & $8.42(2.60)$ & $9.18(2.07)$ & Missing & 9.65 (2.93) & $7.51(1.50)$ & $<0.001$ \\
\hline
\end{tabular}


Table 1. (Continued.)

\begin{tabular}{|c|c|c|c|c|c|c|c|c|c|}
\hline Characteristic & Total & Australia & Canada & UK & Ireland & South Africa & Switzerland & USA & $p^{1}$ \\
\hline \multicolumn{10}{|l|}{ Walking aid (N, \%): } \\
\hline No help & $188(76.7)$ & $29(72.5)$ & $38(86.4)$ & $12(63.2)$ & $31(79.5)$ & $28(70.0)$ & $12(60.0)$ & $38(88.4)$ & 0.057 \\
\hline \multicolumn{10}{|l|}{$\begin{array}{l}\text { Current driving status } \\
(\mathrm{N}, \%) \text { : }\end{array}$} \\
\hline $\begin{array}{l}\text { Mean number of years } \\
\text { driving (SD) }\end{array}$ & $55.79(9.93)$ & $54.77(7.84)$ & $59.29(10.80)$ & $55.00(11.22)$ & $51.16(11.45)$ & Missing & $50.78(9.60)$ & $57.73(9.93)$ & 0.005 \\
\hline \multicolumn{10}{|l|}{$\begin{array}{l}\text { Hours per week driving } \\
(\mathrm{N}, \%) \text { : }\end{array}$} \\
\hline $1-4$ & 78 (48.1) & $13(43.3)$ & $14(33.3)$ & $7(77.8)$ & $14(46.7)$ & Missing & $8(66.7)$ & $22(56.4)$ & \\
\hline $21-22$ & $1(0.6)$ & 0 & 0 & 0 & 0 & & 0 & $1(2.6)$ & \\
\hline
\end{tabular}

Notes: SD: standard deviation. UK: United Kingdom. USA: United States of America. 1. $p$-Values of difference between countries generated using analyses of variance for variables with continuous data and chi-square tests for variables with categorical data. 
Table 2. Use of different transportation methods in good and inclement weather for drivers in rural and city areas (from the modified Transportation Questionnaire)

\begin{tabular}{|c|c|c|c|c|c|}
\hline & \multicolumn{2}{|c|}{ Good weather $^{1}$} & \multicolumn{2}{|c|}{ Inclement weather ${ }^{2}$} & \multirow[b]{2}{*}{$p^{3}$} \\
\hline & Rural & City & Rural & City & \\
\hline & \multicolumn{4}{|c|}{ Frequencies (\%) } & \\
\hline Personal car as driver: & & & & & $0.350(\mathrm{a}), 0.881(\mathrm{~b}),<0.001(\mathrm{c})$ \\
\hline Frequently & $63(75.0)$ & $97(82.9)$ & $36(43.9)$ & $42(49.4)$ & \\
\hline Rarely & $19(22.6)$ & $19(16.2)$ & $33(40.2)$ & $33(38.8)$ & \\
\hline Never & $2(2.4)$ & $1(0.9)$ & $13(15.9)$ & $10(11.8)$ & \\
\hline Personal car passenger: & & & & & $0.281(\mathrm{a}), 0.618(\mathrm{~b}), 0.516(\mathrm{c})$ \\
\hline Frequently & $8(9.5)$ & $18(15.4)$ & $12(14.5)$ & $8(9.4)$ & \\
\hline Rarely & $45(53.6)$ & $58(49.6)$ & $32(38.6)$ & $43(50.6)$ & \\
\hline Never & $31(36.9)$ & $41(35.0)$ & $39(47.0)$ & $34(40.0)$ & \\
\hline Public transport bus: & & & & & $\mathrm{n} / \mathrm{a}$ \\
\hline Frequently & $9(10.6)$ & $2(1.7)$ & $7(8.2)$ & $3(3.5)$ & \\
\hline Rarely & $17(20.0)$ & $26(22.2)$ & $11(12.9)$ & $19(22.4)$ & \\
\hline Never & $59(69.4)$ & $89(76.1)$ & $67(78.8)$ & $63(74.1)$ & \\
\hline Public transport train: & & & & & $\mathrm{n} / \mathrm{a}$ \\
\hline Frequently & $2(2.4)$ & 0 & $1(1.2)$ & $1(1.2)$ & \\
\hline Rarely & $19(22.4)$ & $25(21.4)$ & $14(16.5)$ & $22(25.9)$ & \\
\hline Never & $64(75.3)$ & $92(78.6)$ & $70(82.3)$ & $62(72.9)$ & \\
\hline Public transport tram: & & & & & $\mathrm{n} / \mathrm{a}$ \\
\hline Frequently & $1(1.2)$ & $3(2.6)$ & 0 & $3(4.2)$ & \\
\hline Rarely & $7(8.5)$ & $29(24.8)$ & $6(10.3)$ & $26(36.1)$ & \\
\hline Never & $74(90.2)$ & 85 (72.6) & $52(89.7)$ & $43(59.7)$ & \\
\hline
\end{tabular}


Table 2. (Continued.)

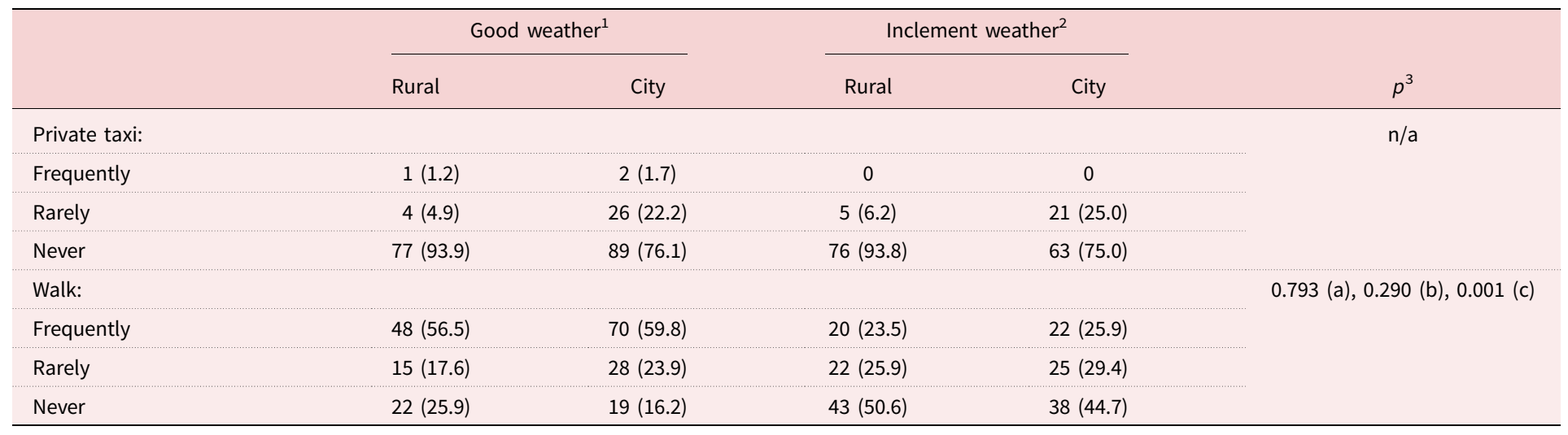

Notes: 1. $\mathrm{N}$ ranging from 82 to 117. 2. $\mathrm{N}$ ranging from 81 to $85.3 . p$-Values generated using chi-square tests: (a) difference between rural and city drivers in good weather; (b) difference between rural and city drivers in inclement weather; (c) difference between all drivers, in good and inclement weather. $\mathrm{n} / \mathrm{a}$ : not applicable - does not meet minimum expected cell frequency, therefore unable to calculate. 
Table 3. The frequency of drivers avoiding specific driving conditions over the last three months and differences between city versus rural drivers (from the modified Transportation Questionnaire)

\begin{tabular}{lcccc}
\hline & Frequently & Rarely & Never & $p^{1}$ \\
\hline & \multicolumn{5}{c}{ Frequencies (\%) } \\
\hline Driving at night & $57(28.2)$ & $61(30.2)$ & $84(41.6)$ & 0.291 \\
\hline Making right/left turns across traffic & $9(4.5)$ & $25(12.4)$ & $168(83.1)$ & 0.082 \\
\hline Driving in bad weather & $51(25.2)$ & $74(36.6)$ & $77(38.2)$ & 0.408 \\
\hline Driving on high-traffic roads & $34(16.8)$ & $42(20.8)$ & $126(62.4)$ & 0.734 \\
\hline Driving in unfamiliar areas & $38(18.8)$ & $51(25.3)$ & $113(55.9)$ & 0.926 \\
\hline $\begin{array}{l}\text { Pass up opportunities to go out because } \\
\text { of concerns about driving }\end{array}$ & $7(3.5)$ & $26(12.9)$ & $169(83.7)$ & 0.914 \\
\hline
\end{tabular}

Notes: $\mathrm{N}=202$. 1 . Chi-square test used to generate $p$-values of difference between city and rural drivers.

found (see Table 3). There was also no difference in driving avoidance between the three age groups: $\leqslant 73$ years $(38 \%), 74-80$ years $(33 \%)$ and $\geqslant 81$ years $(29 \%)$ $(p=0.125)$, nor between male and female participants (36.6 and 63.4\%) $(p=0.323)$.

\section{Transport used by older drivers and non-drivers to access out-of-home places, and differences in places accessed}

Table 4 presents the differences between drivers and non-drivers in terms of the T-ACT-OUT places they identified going to, and the modes of transportation used to access these places. The frequency of using public transport to attend out-of-home places, as recorded on the T-ACT-OUT, was generally low for both drivers and non-drivers. The frequency regarding the type of transportation used to access different locations varied, which may be related to the occupation or activity being completed in the specific location. For example, passenger frequencies were highest for attending a hospital or a transportation hub (depot) and walking frequencies were highest when accessing activities in one's neighbourhood.

Chi-square tests demonstrated significant differences between how many locations drivers, as compared to non-drivers, attended out-of-home activities for eight of 21 locations in the T-ACT-OUT: supermarket, pharmacy, bank/post office, family/ friends, entertainment, seaside, neighbourhood and sport facilities. In all cases, more drivers recorded attendance at such locations, suggesting a higher level of participation and engagement in the community among these participants. Differences were seen in three of the four clusters of locations of these activities (consumer, administrative and self-care places; social, cultural and spiritual places; and places for recreational and physical activities). There were no differences between drivers and non-drivers in places associated with the medical care cluster (i.e. doctor, hospital, therapy and day care), suggesting equal participation in these locations.

\section{Quality of life and life satisfaction for drivers and non-drivers}

There were significant differences in health-related quality of life among participants, with drivers reporting higher levels on the EQ-5D-5L-VAS (mean $=79.1$, 
Table 4. Difference in drivers versus non-drivers currently attending places and transport type used to get there (from Transport - Participation in Activities and Places Outside the Home (T-ACT-OUT))

\begin{tabular}{|c|c|c|c|c|c|c|}
\hline \multirow[b]{2}{*}{ T-ACT-OUT place } & \multirow[b]{2}{*}{ No - don't currently attend } & \multirow[b]{2}{*}{ Yes - currently attend } & \multirow[b]{2}{*}{$p^{1}$} & \multicolumn{3}{|c|}{ Transport type used to attend T-ACT-OUT place ${ }^{2}$} \\
\hline & & & & Transport & Drivers & Non-drivers \\
\hline & Frequencies (\%) & & \multicolumn{4}{|c|}{ Frequencies (\%) } \\
\hline Grocery: & & & & Drive & $72(35.6)$ & 0 \\
\hline Driver & $53(26.2)$ & $149(73.8)$ & & Walk & $40(19.8)$ & $14(31.8)$ \\
\hline \multirow[t]{3}{*}{ Non-driver } & $17(38.6)$ & $27(61.4)$ & 0.142 & Passenger & $5(2.5)$ & $6(13.6)$ \\
\hline & & & & Bus & 0 & $1(0.4)$ \\
\hline & & & & Missing & $32(15.8)$ & $6(13.6)$ \\
\hline Supermarket: & & & & Drive & $137(67)$ & 0 \\
\hline Driver & $13(6.4)$ & $189(93.6)$ & & Walk & $11(5.4)$ & $10(22.7)$ \\
\hline \multirow[t]{5}{*}{ Non-driver } & $11(25.0)$ & $33(75.0)$ & 0.001 & Passenger & $13(6.4)$ & $14(31.8)$ \\
\hline & & & & Bus & $1(0.5)$ & $3(6.8)$ \\
\hline & & & & Train & $1(0.4)$ & 0 \\
\hline & & & & Taxi & 0 & $1(2.3)$ \\
\hline & & & & Missing & $26(12.9)$ & $5(11.4)$ \\
\hline Pharmacy: & & & & Drive & $109(54.0)$ & 0 \\
\hline Driver & $14(6.9)$ & $188(93.1)$ & 0.038 & Walk & $39(19.3)$ & $20(45.5)$ \\
\hline \multirow[t]{3}{*}{ Non-driver } & $8(18.2)$ & $36(81.8)$ & & Passenger & $7(3.5)$ & $7(15.9)$ \\
\hline & & & & Bus & $2(1.0)$ & $3(6.8)$ \\
\hline & & & & Missing & $31(15.3)$ & $6(13.6)$ \\
\hline
\end{tabular}




\begin{tabular}{|c|c|c|c|c|c|c|}
\hline Hairdresser: & & & & Drive & $108(53.5)$ & \\
\hline Driver & $36(17.8)$ & $166(82.2)$ & & Walk & $19(9.4)$ & $14(31.8)$ \\
\hline \multirow[t]{6}{*}{ Non-driver } & $12(27.3)$ & $32(72.7)$ & 0.221 & Passenger & $2(1.0)$ & $4(9.1)$ \\
\hline & & & & Bus & $4(2.0)$ & $4(9.1)$ \\
\hline & & & & Train & $5(2.5)$ & $1(2.3)$ \\
\hline & & & & Tram & 0 & $1(2.3)$ \\
\hline & & & & Taxi & 0 & $1(2.3)$ \\
\hline & & & & Missing & $28(13.9)$ & $7(15.9)$ \\
\hline Bank/post office: & & & & Drive & $113(55.9)$ & 0 \\
\hline Driver & $20(9.9)$ & $182(90.1)$ & & Walk & $42(20.8)$ & $20(45.5)$ \\
\hline \multirow[t]{6}{*}{ Non-driver } & $10(22.7)$ & $34(77.3)$ & 0.036 & Passenger & $4(2.0)$ & $5(11.4)$ \\
\hline & & & & Bus & $2(1.0)$ & $3(6.8)$ \\
\hline & & & & Train & $1(0.5)$ & 0 \\
\hline & & & & Tram & 0 & $1(2.3)$ \\
\hline & & & & Taxi & 0 & $1(2.3)$ \\
\hline & & & & Missing & $20(9.9)$ & $4(9.1)$ \\
\hline Town hall: & & & & Drive & $65(32.2)$ & 0 \\
\hline Driver & $107(53.0)$ & $95(47.0)$ & & Walk & $9(4.5)$ & $7(15.9)$ \\
\hline \multirow[t]{5}{*}{ Non-driver } & $31(70.5)$ & $13(29.5)$ & 0.051 & Passenger & $3(1.5)$ & $1(2.3)$ \\
\hline & & & & Bus & 0 & $2(4.5)$ \\
\hline & & & & Train & $2(1.0)$ & $1(2.3)$ \\
\hline & & & & Tram & 0 & $1(2.3)$ \\
\hline & & & & Missing & $16(7.9)$ & $1(2.3)$ \\
\hline
\end{tabular}


Table 4. (Continued.)

\begin{tabular}{|c|c|c|c|c|c|c|}
\hline \multirow[b]{2}{*}{ T-ACT-OUT place } & \multirow[b]{2}{*}{ No - don't currently attend } & \multirow[b]{2}{*}{ Yes - currently attend } & \multirow[b]{2}{*}{$p^{1}$} & \multicolumn{3}{|c|}{ Transport type used to attend T-ACT-OUT place ${ }^{2}$} \\
\hline & & & & Transport & Drivers & Non-drivers \\
\hline Doctor/dentist: & & & & Drive & $127(62.9)$ & 0 \\
\hline Driver & $4(2.0)$ & $198(98.0)$ & & Walk & $23(11.4)$ & $18(40.9)$ \\
\hline \multirow[t]{6}{*}{ Non-driver } & $3(6.8)$ & $41(93.2)$ & 0.212 & Passenger & $5(2.5)$ & $11(25.0)$ \\
\hline & & & & Bus & $11(5.4)$ & $4(9.1)$ \\
\hline & & & & Train & $2(1.0)$ & 0 \\
\hline & & & & Tram & $1(0.5)$ & 0 \\
\hline & & & & Taxi & $1(0.5)$ & $2(4.5)$ \\
\hline & & & & Missing & $28(13.9)$ & $6(13.6)$ \\
\hline Hospital: & & & & Drive & $70(34.7)$ & 0 \\
\hline Driver & $86(42.6)$ & $116(57.4)$ & & Walk & $4(2.0)$ & $2(4.5)$ \\
\hline \multirow[t]{6}{*}{ Non-driver } & $15(34.1)$ & $29(65.9)$ & 0.386 & Passenger & $16(7.9)$ & $10(22.7)$ \\
\hline & & & & Bus & $7(3.5)$ & $8(18.2)$ \\
\hline & & & & Train & $5(2.5)$ & 0 \\
\hline & & & & Tram & $1(0.5)$ & $1(2.3)$ \\
\hline & & & & Taxi & 0 & $4(9.1)$ \\
\hline & & & & Missing & $13(6.4)$ & $4(9.1)$ \\
\hline Therapy: & & & & Drive & $32(15.8)$ & 0 \\
\hline Driver & $155(76.7)$ & $47(23.3)$ & & Walk & $6(3.0)$ & $6(13.6)$ \\
\hline Non-driver & $27(61.4)$ & $17(38.6)$ & 0.055 & Passenger & $1(0.5)$ & $3(6.8)$ \\
\hline
\end{tabular}




\begin{tabular}{|c|c|c|c|c|c|c|}
\hline & & & & Bus & $1(0.5)$ & $4(9.1)$ \\
\hline & & & & Train & $1(0.5)$ & 0 \\
\hline & & & & Taxi & 0 & $2(4.5)$ \\
\hline & & & & Missing & $6(3.0)$ & $2(4.5)$ \\
\hline Day care: & & & & Drive & $1(0.5)$ & 0 \\
\hline Driver & $200(99.0)$ & $1(0.5)$ & & Bus & 0 & $1(2.3)$ \\
\hline Non-driver & $40(90.9)$ & $1(2.3)$ & 0.760 & Missing & $1(0.5)$ & $3(6.8)$ \\
\hline Missing & $4(7.3)$ & & & & & \\
\hline Friend/family: & & & & Drive & $121(59.9)$ & 0 \\
\hline Driver & $18(8.9)$ & $184(91.1)$ & & Walk & $14(6.9)$ & $5(11.4)$ \\
\hline \multirow[t]{5}{*}{ Non-driver } & \multirow[t]{5}{*}{$10(22.7)$} & \multirow[t]{5}{*}{$34(77.3)$} & \multirow[t]{5}{*}{0.019} & Passenger & $14(6.9)$ & $10(22.7)$ \\
\hline & & & & Bus & $2(1.0)$ & $9(20.5)$ \\
\hline & & & & Train & $3(1.5)$ & $1(2.3)$ \\
\hline & & & & Tram & 0 & $1(2.3)$ \\
\hline & & & & Missing & 30 (14.9) & $8(18.2)$ \\
\hline \multicolumn{4}{|l|}{ Restaurant: } & Drive & $108(53.5)$ & 0 \\
\hline Driver & $11(5.4)$ & $191(94.6)$ & & Walk & $26(12.9)$ & $11(25.0)$ \\
\hline \multirow[t]{6}{*}{ Non-driver } & \multirow[t]{6}{*}{$5(11.4)$} & \multirow[t]{6}{*}{$39(88.6)$} & \multirow[t]{6}{*}{0.269} & Passenger & $16(7.9)$ & $4(9.1)$ \\
\hline & & & & Bus & $3(1.5)$ & $12(27.3)$ \\
\hline & & & & Train & $2(1.0)$ & 0 \\
\hline & & & & Tram & 0 & $2(4.5)$ \\
\hline & & & & Taxi & 0 & $1(2.3)$ \\
\hline & & & & Missing & $36(17.8)$ & $9(20.5)$ \\
\hline
\end{tabular}


Table 4. (Continued.)

\begin{tabular}{|c|c|c|c|c|c|c|}
\hline \multirow[b]{2}{*}{ T-ACT-OUT place } & \multirow[b]{2}{*}{ No - don't currently attend } & \multirow[b]{2}{*}{ Yes - currently attend } & \multirow[b]{2}{*}{$p^{1}$} & \multicolumn{3}{|c|}{ Transport type used to attend T-ACT-OUT place ${ }^{2}$} \\
\hline & & & & Transport & Drivers & Non-drivers \\
\hline Seniors centre: & & & & Drive & $59(29.2)$ & 0 \\
\hline Driver & $93(46.0)$ & $109(54.0)$ & & Walk & $10(5.0)$ & $7(15.9)$ \\
\hline Non-driver & $17(38.6)$ & $26(59.1)$ & & Passenger & $3(1.5)$ & $6(13.6)$ \\
\hline \multirow[t]{3}{*}{ Missing } & $1(2.3)$ & & 0.542 & Bus & $1(0.5)$ & $7(15.9)$ \\
\hline & & & & Train & $3(1.5)$ & 0 \\
\hline & & & & Missing & $33(16.3)$ & $7(15.9)$ \\
\hline Worship: & & & & Drive & $87(43.1)$ & 0 \\
\hline Driver & $80(39.6)$ & $122(60.4)$ & & Walk & $10(5.0)$ & $12(27.3)$ \\
\hline \multirow[t]{4}{*}{ Non-driver } & $16(36.4)$ & $28(63.6)$ & 0.819 & Passenger & $9(4.5)$ & $8(18.2)$ \\
\hline & & & & Bus & $2(1.0)$ & $2(4.5)$ \\
\hline & & & & Train & $1(0.5)$ & 0 \\
\hline & & & & Missing & $13(6.4)$ & $6(13.6)$ \\
\hline Entertainment: & & & & Drive & $90(44.6)$ & 0 \\
\hline Driver & $36(17.8)$ & $166(82.2)$ & & Walk & $6(3.0)$ & $2(4.5)$ \\
\hline \multirow[t]{6}{*}{ Non-driver } & $17(38.6)$ & $27(61.4)$ & 0.004 & Passenger & $21(10.4)$ & 5 (11.4) \\
\hline & & & & Bus & $8(4.0)$ & $6(13.6)$ \\
\hline & & & & Train & $8(4.0)$ & $4(9.1)$ \\
\hline & & & & Tram & $3(1.5)$ & $1(2.3)$ \\
\hline & & & & Taxi & $2(1.0)$ & $1(2.3)$ \\
\hline & & & & Missing & $28(13.9)$ & $8(18.2)$ \\
\hline
\end{tabular}




\begin{tabular}{|c|c|c|c|c|c|c|}
\hline Park: & & & & Drive & $41(20.3)$ & \\
\hline Driver & $72(35.6)$ & $130(64.4)$ & & Walk & $55(27.2)$ & $10(22.7)$ \\
\hline \multirow[t]{3}{*}{ Non-driver } & $21(47.7)$ & $23(52.3)$ & 0.185 & Passenger & $5(2.5)$ & 5 (11.4) \\
\hline & & & & Bus & $1(0.5)$ & $3(6.8)$ \\
\hline & & & & Missing & $28(13.9)$ & 5 (11.4) \\
\hline Seaside/forest: & & & & Drive & $64(31.7)$ & 0 \\
\hline Driver & $71(35.1)$ & $131(64.9)$ & & Walk & $19(9.4)$ & $1(2.3)$ \\
\hline \multirow[t]{6}{*}{ Non-driver } & $24(54.5)$ & $20(45.5)$ & 0.026 & Passenger & $11(5.4)$ & $8(18.2)$ \\
\hline & & & & Bus & $5(2.5)$ & $3(6.8)$ \\
\hline & & & & Train & $3(1.5)$ & $1(2.3)$ \\
\hline & & & & Tram & 0 & $1(0.4)$ \\
\hline & & & & Fly & $8(4.0)$ & $2(4.5)$ \\
\hline & & & & Missing & $21(10.4)$ & $4(9.1)$ \\
\hline Cottage: & & & & Drive & $34(16.8)$ & 0 \\
\hline Driver & $144(71.3)$ & $58(28.7)$ & & Passenger & $3(1.5)$ & $3(6.8)$ \\
\hline \multirow[t]{4}{*}{ Non-driver } & $35(79.5)$ & $9(20.5)$ & 0.353 & Bus & 0 & $1(2.3)$ \\
\hline & & & & Train & $2(1.0)$ & 0 \\
\hline & & & & Fly & $3(1.5)$ & $2(4.5)$ \\
\hline & & & & Missing & $16(7.9)$ & $3(6.8)$ \\
\hline Neighbourhood: & & & & Drive & $7(3.5)$ & 0 \\
\hline Driver & $40(19.8)$ & $162(80.2)$ & & Walk & $124(61.4)$ & $21(47.7)$ \\
\hline Non-driver & $17(38.6)$ & $27(61.4)$ & 0.013 & Missing & $31(15.3)$ & 6 (13.6) \\
\hline
\end{tabular}


Table 4. (Continued.)

\begin{tabular}{|c|c|c|c|c|c|c|}
\hline \multirow[b]{2}{*}{ T-ACT-OUT place } & \multirow[b]{2}{*}{ No-don't currently attend } & \multirow[b]{2}{*}{ Yes - currently attend } & \multirow[b]{2}{*}{$p^{1}$} & \multicolumn{3}{|c|}{ Transport type used to attend T-ACT-OUT place $^{2}$} \\
\hline & & & & Transport & Drivers & Non-drivers \\
\hline Sport facility: & & & & Drive & $64(31.7)$ & 0 \\
\hline Driver & $103(51.0)$ & $99(49.0)$ & & Walk & $12(5.9)$ & $4(9.1)$ \\
\hline \multirow[t]{6}{*}{ Non-driver } & $31(70.5)$ & $13(29.5)$ & 0.029 & Passenger & $1(0.5)$ & $1(2.3)$ \\
\hline & & & & Bus & $1(0.5)$ & $2(4.5)$ \\
\hline & & & & Train & $1(0.5)$ & 0 \\
\hline & & & & Tram & 0 & $1(2.3)$ \\
\hline & & & & Taxi & 0 & $1(2.3)$ \\
\hline & & & & Missing & $20(9.9)$ & $4(9.1)$ \\
\hline Transport centre: & & & & Drive & $45(22.3)$ & 0 \\
\hline Driver & $59(29.2)$ & $143(70.8)$ & & Walk & $11(5.4)$ & $1(2.3)$ \\
\hline \multirow[t]{6}{*}{ Non-driver } & 15 (34.1) & $29(65.9)$ & 0.647 & Passenger & $26(12.9)$ & $10(22.7)$ \\
\hline & & & & Bus & $14(6.9)$ & $4(9.1)$ \\
\hline & & & & Train & $4(2.0)$ & $1(2.3)$ \\
\hline & & & & Tram & $1(0.5)$ & $2(4.5)$ \\
\hline & & & & Taxi & $19(9.4)$ & $5(11.4)$ \\
\hline & & & & Missing & $23(11.4)$ & $6(13.6)$ \\
\hline
\end{tabular}


$\mathrm{SD}=14.9)$ compared with non-drivers (mean $=72.47, \mathrm{SD}=17.2)(p=0.011,95 \%$ confidence interval $=1.57-11.71)$. However, satisfaction with life was not significantly different between drivers and non-drivers, when investigated with the T-ACT-OUT categories for drivers/non-drivers $(p=0.802)$.

\section{Discussion}

This research examined the mobility patterns of older drivers and non-drivers from seven countries and documented their out-of-home activities and quality of life. Initially, the paper examined demographic factors, such as age and gender, health status and driving status, across participants. Although some differences between participants from different countries were identified, this research, as well as the research from others (Choi et al., 2012; Gardner, 2014), suggests a complex mosaic of factors combine to impact community mobility. As such, our research team determined investigating associated activity patterns across participants in an international sample as more valuable than examining relationships according to country per se. The second aim related to exploring the impact of age, gender, weather, time of day, road type, traffic volume, and city versus rural location on driving patterns of older drivers, and avoidance of particular driving conditions. Our findings suggested weather was a major factor impacting access to out-of-home activities. All drivers (living in rural and city areas) drove less frequently and walked less frequently in inclement weather but their use of public transport did not increase in this weather. In terms of the types of transportation used by older drivers and nondrivers to access out-of-home places, we found that driving was the most common form of transport, and that drivers were accessing many more out-of-home places and activities than non-drivers. The final aim of the study was to investigate if there were any differences between drivers and non-drivers on two measures of quality of life. The findings showed that quality of life was generally high among all participants, but slightly higher for drivers when compared to non-drivers. However, given that only a small difference between the groups was identified for only one of the measures, this finding requires further investigation.

\section{Characteristics of participants from seven countries}

The participants in this research were from seven countries, and although the samples were generally well-educated and self-identified as relatively healthy, there were several notable differences. There was a higher proportion of participants in Canada who were urban dwellers compared to those recruited from the USA, Ireland and UK who were predominantly from rural areas; the proportion of participants in Ireland without a tertiary qualification was higher than in other countries, and the Irish population also reported the lowest quality of life on the EQ-5D-5L. Most of the participants in Ireland were drivers, which may be reflective that a high proportion were rural dwellers, and there were also higher proportions of participants from Canada and the USA who were drivers when compared to the UK and Switzerland. Further investigations comparing non-drivers with drivers from different countries were not possible as sample sizes of non-drivers were not sufficiently large. As noted above, while the findings suggest a need to cross-compare 
differences in countries in future research, it was valuable to analyse our data for drivers and non-drivers, across the seven countries (Choi et al., 2012; Gardner, 2014).

\section{Relationship between mode of transportation on age, gender, weather and location and participation in community activities}

Similar to Vrkljan et al. (2011) and Hagan (2020), who all identified the important role of transportation on the ability of older adults to age-in-place, findings from the current study also support the notion of transportation as an enabler of living well in later life. Our analysis indicated 82 per cent of our sample, which was comprised of community-dwelling older adults, were still driving. Passenger frequencies were highest, however, when participants needed to access hospital services, or transport hubs (depots), which was also identified by Vrkljan et al. (2011). As raised by Gardner (2014), the reason a driver might choose to use their own vehicle, public transport or be a passenger, is often complex and for a myriad of purposes. The results from the T-ACT-OUT suggested more drivers, as compared to nondrivers, were accessing a wide variety of places, such as the supermarket, entertainment, pharmacies, bank/post office, municipal offices, therapy, visiting the seaside or forest, their own neighbourhood, sporting facilities, as well as visiting with friends and family. Hence this research indicates that being a driver, across all represented countries, can support greater community participation and engagement in a range of out-of-home activities. This finding resonates with recent evidence, which suggests supporting older drivers to continue to drive for as long as possible to maintain access to their communities is critical (O'Neill et al., 2019). In fact, the findings in Table 4 emphasise that driving, followed by walking and being a passenger in a private vehicle, are the most frequently used transportation options for older adults when it came to the 21 places captured in T-ACT-OUT. However, there were a small number of participants who indicated using public transportation, particularly among city dwellers whom it is assumed have greater availability of public transportation, which warrants further investigation with larger samples in the future to understand what may promote and support public transportation use in later life. As such, the question remains as to whether low use of public transportation is linked to a lack of nearby services, or even a reluctance to use existing services, which could be due to fear or other safety-related issues in their neighbourhood (Levasseur et al., 2015), or perhaps an over-reliance and familiarity with using their private car, as the primary source of transport. As pointed out by Foley et al. (2002), many older people are likely to outlive their driving years, therefore in order to maintain their level of out-of-home engagements, the findings from our study indicate a need to address this over-reliance on driving. The findings suggest there is a need to enable older adults to prepare to transition from being drivers to non-drivers and engage more effectively with public transportation options if such options are available, to support living well in later life.

The results on the Transportation Questionnaire also indicated drivers reduced or avoided driving in inclement weather, which may indicate good levels of self-awareness and self-regulation regarding driving patterns. However, these 
participants did not increase their use of public transport in such conditions, which suggests they simply remain at home. A GPS-based analysis conducted by Smith et al. (2016) of older Canadian drivers found they took shorter trips during the winter months. However, unexpectedly, they also reported that these older drivers also took longer trips at night, even when controlling for weather conditions. Similarly, in our study, 71.8 per cent of participants rarely or never reduced their frequency of night driving. All these research findings suggest that a complex myriad of factors is at play regarding the driving patterns and community engagement of older people. Smith et al. (2016) suggested city planners and traffic engineers consider that if older drivers are using roadways at night and during inclement weather, they should improve signage, maintenance including snow clearing and streetlights, and this would support the safety of all road users. Findings from the current study also support the need to increase the accessibility of public transport as an alternative to the private automobile for older people to maintain access to their out-of-home activities, even in poor weather.

\section{Quality of life and life satisfaction for drivers and non-drivers}

The final research aim related to exploring differences in quality of life and life satisfaction between study participants who did and did not drive. Our research, as well as other research evidence and commentaries, highlight the critical role of transportation on quality of life and life satisfaction in older adulthood (Rantakokko et al., 2013; Zeitler and Buys, 2015; O’Neill et al., 2019). However, while our findings on the EQ-5D-5L-VAS showed a statistically significant difference between drivers and non-drivers, the mean difference was only 6.6 points, which on a scale of 100 points is potentially not clinically meaningful. Unfortunately, we could not locate any prior studies reporting EQ-5D-5L-VAS scores for drivers versus non-drivers, necessitating future data collection using this measure. When overall quality of life was measured on the four-level Likert-type scale on the T-ACT-OUT, there were no differences between drivers and non-drivers. This finding, coupled with the small difference between drivers and non-drivers on the EQ-5D-5L-VAS, suggests most older adults in the current study are still able to do what they expect and want to do, but that further investigations regarding any differences in quality of life between older drivers and nondrivers are required.

\section{Limitations}

This research presents insights into the patterns of transport use by older people across seven countries, however, several limitations must be acknowledged. The convenience sampling strategy meant participants represented a relatively well and active group of older people, the majority of whom drove. The smaller sample size for non-drivers limited our ability to examine between-country differences between these groups. In addition, research using semi-structured interviews are subject to a range of limitations, including participant responses being affected by the season of data collection. For example, if interviews were conducted in the summer, it may be more difficult for people to report on transport use in 
the winter. The income status of participants was also not collected in this study given the difficulties associated with capturing accurate, ethical, meaningful, yet non-invasive data on this measure across the seven countries involved. In the future, such data could be used to determine if transportation access and associated activity involvement and life satisfaction is linked to income status, and if further interventions can redress any inequities found. In addition, we did not collect data on whether participants lived with a partner or spouse (and that person's driving status) and acknowledge that future studies could gather more detailed data on the circle of people around the participant and how the number, relationship, transport access and geographical proximity of these people influence transport patterns. Cross-country comparisons were not possible on each variable, as not all locations used all forms of transport (e.g. light rail). In addition, some definitions on the T-ACT-OUT require further refinement regarding language used, as terms such as 'bad weather' have particular contextual meaning for some countries. For example, countries with more severe winters (e.g. Canada, Switzerland) may have perceived this terminology differently from those with very hot weather conditions, such as South Africa or Australia, where heat may not have been associated with 'bad weather'. Finally, while the datasets were complete in most countries, the South African data collection was limited, with only sections of the demographics, Transportation Questionnaire and T-ACT-OUT administered. Future studies should consider adopting more representative sampling techniques and, for certain variables, such as socio-economic status, incorporate strategies using other databases or census data.

\section{Conclusions}

This study is first to our knowledge to collect data from community-dwelling older adults from seven countries to examine patterns of transport and out-of-home activities with a focus on differences between drivers and non-drivers. While our analyses found weather was a major factor that impacted out-of-home activities, use of public transportation did not increase under inclement weather conditions, suggesting further attention should be paid to make public transportation more accessible to people when the weather makes it more challenging to go out. Drivers in our study were accessing many more out-of-home places and activities than non-drivers, suggesting higher community participation among those who were driving. This finding is congruent with the findings of other international studies that call for programmes that support older people to drive safely for longer (Sangrar et al., 2019). Finally, this research found that quality of life was generally high among all participants, but slightly higher for drivers when compared to nondrivers. Since many studies have shown that quality of life and life satisfaction are impacted by access to safe transportation, research, policy and practice should focus on developing strategies that assist older people to maintain transport and, in turn, their access to out-of-home activities. Given the complexity of mobility patterns and use of transport, an individualised approach may be necessary to support older adults transition from driving to driving cessation by using modes of transport that keep them connected to their community regardless of their age, ability and where they live. 
Acknowledgements. We gratefully acknowledge Professor Paul Vaucher for initial discussions on this topic that led to organising the first think tank and meeting for our group. We also acknowledge the work of the following people who assisted in data collection: Australia: Edward Hill, BSc (Hons), PhD; Canada: Rivi Levkovich, MA and Yu-Ting Chen, PhD; Ireland: Dr Catherine Elliott O'Dare; South Africa: Courtney Hickson, Ermen Venter, Rene' Potgieter, Samantha Sephton and Talita Stapelberg; Switzerland: Aurélie Sohier, MSc-OT; UK: Carole McCarthy, MSc, DipPT and Holli Singer, MSc, DipCOT, both from Brunel Partners' Academic Centre for Health Sciences, Uxbridge, UK; USA: Juliette Leonardo, OTS, Eleanor Hodge, OTS and Alyssa Paul, OTS.

Author contributions. All authors contributed to the development of the research questions, design of the study, collecting data and overseeing data collection with research assistants, and reviewing and commenting on drafts of the analyses and then drafts of the paper. PH and CU drafted and led the ethics application, and each author subsequently managed this process at their institution. CU and AT undertook the data analyses and prepared the initial draft of the manuscript. All authors contributed to subsequent drafts of the paper.

Financial support. A grant to hold a scientific meeting from the University of Applied Sciences and Arts of Western Switzerland enabled our international team to gather in 2016 and commence an international collaboration called the International Expert Advisory Panel on Community Health and Transport (I-CHAT) (Vaucher et al., 2017).

Conflict of interest. The authors declare no potential conflicts of interest with respect to the research, authorship and/or publication of this article.

Ethical standards. The research was initially approved by the Brunel University London Ethics Committee (reference number 11103-LR-Jul/2018-13377-3), and subsequently approved by the Institutional Review Boards or Ethics Committees at the universities or research institutions of all the participating authors.

\section{References}

Ahn M, Kwon HJ and Kang J (2020) Supporting aging-in-place well: findings from a cluster analysis of the reasons for aging-in-place and perceptions of well-being. Journal of Applied Gerontology 39, 3-15.

Austroads and National Transport Commission (2016) Assessing Fitness to Drive for Commercial and Private Vehicle Drivers, 5th Edn. Sydney: Austroads.

Centers for Disease Control and Prevention and National Center for Health Statistics (2018) Health, United States 2018. Available at https://www.cdc.gov/nchs/hus/index.htm.

Chao T-Y (2018) Planning for Greying Cities: Age-friendly City Planning and Design Research and Practice. New York, NY: Routledge.

Choi M, Adams KB and Kahana E (2012) The impact of transportation support on driving cessation among community-dwelling older adults. Journals of Gerontology: Psychological Sciences and Social Sciences 67B, 392-400.

Choi M, Lohman MC and Mezuk B (2014) Trajectories of cognitive decline by driving mobility: evidence from the Health and Retirement Study. International Journal of Geriatric Psychiatry 29, 447-453.

Choi M, O'Connor ML, Mingo CA and Mezuk B (2015) Gender and racial disparities in life-space constriction among older adults. The Gerontologist 56, 1153-1160.

Christiansen C and Townsend E (2014) Introduction to Occupation: The Art and Science of Living, 2nd Edn. Harlow, UK: Pearson.

Dahan-Oliel N, Mazer B, Gélinas I, Dobbs B and Lefebvre H (2010) Transportation use in community-dwelling older adults: association with participation and leisure activities. Canadian Journal on Aging/La revue canadienne du vieillissement 29, 491-502.

Dickerson AE, Molnar LJ, Bédard M, Eby DW, Berg-Weger M, Choi M, Grigg J, Horowitz A, Meuser T, Myers A, O'Connor M and Silverstein N (2019) Transportation and aging: an updated research agenda to advance safe mobility among older adults transitioning from driving to non-driving. The Gerontologist 59, 215-221. 
Foley DJ, Heimovitz HK, Guralnik JM and Brock DB (2002) Driving life expectancy of persons aged 70 years and older in the United States. American Journal of Public Health 92, 1284-1289.

Fristedt S, Dahl AK, Wretstrand A, Björklund A and Falkmer T (2014) Changes in community mobility in older men and women. A 13-year prospective study. PLOS ONE 9, e87827.

Gardner P (2014) The role of social engagement and identity in community mobility among older adults aging in place. Disability and Rehabilitation 36, 1249-1257.

Golant SM and LaGreca AJ (1994) Housing quality of U.S. elderly households: does aging in place matter? The Gerontologist 34, 803-814.

Granger C, Albrecht G and Hamilton B (1979) Outcome of comprehensive medical rehabilitation: measurement by PULSES profile and the Barthel Index. Archives of Physical Medicine and Rehabilitation 60, $145-154$.

Hagan R (2020) Getting out of the house: the use of community transport as a third place for rural dwelling older adults. Ageing \& Society 40, 2519-2539.

Herdman M, Gudex C, Lloyd A, Janssen M, Kind P, Parkin D, Bonsel G and Badia X (2011) Development and preliminary testing of the new five-level version of EQ-5D (EQ-5D-5L). Quality of Life Research 20, 1727-1736.

Koppel S, Charlton JL, Langford J, Di Stefano M, MacDonald W, Vlahodimitrakou Z and Eliasz K (2016) Driving task: how older drivers' on-road driving performance relates to abilities, perceptions, and restrictions. Canadian Journal on Aging/La revue canadienne du vieillissement 35, 15-31.

Krishnasamy C, Unsworth CA and Howie L (2011) The patterns of activity, and transport to activities among older adults in Singapore. Hong Kong Journal of Occupational Therapy 21, 80-87.

Krishnasamy C, Unsworth CA and Howie L (2013) Exploring the mobility preferences and perceived difficulties in using transport and driving with a sample of healthy and outpatient older adults in Singapore. Australian Occupational Therapy Journal 60, 129-137.

Levasseur M, Audet T, Gelinas I, Bedard M, Langlais MẼ, Therrien FH, Renaud J-C, Coallier J and D'Amours M (2015) Awareness tool for safe and responsible driving (OSCAR): a potential educational intervention for increasing interest, openness and knowledge about the abilities required and compensatory strategies among older drivers. Traffic Injury Prevention 16, 578-586.

Levasseur M, Généreux M, Bruneau JF, Vanasse A, Chabot É, Beaulac C and Bédard MM (2015) Importance of proximity to resources, social support, transportation and neighborhood security for mobility and social participation in older adults: results from a scoping study. BMC Public Health 15, 503.

Liddle J, Gustafsson L, Bartlett $\mathbf{H}$ and McKenna K (2012) Time use, role participation and life satisfaction of older people: impact of driving status. Australian Occupational Therapy Journal 59, 384-392.

Loyd C, Beasley TM, Miltner RS, Clark D, King B and Brown CJ (2018) Trajectories of community mobility recovery after hospitalization in older adults. Journal of the American Geriatrics Society 66, 1399-1403.

Lynott J, Haase J, Nelson K, Taylor A, Twaddell H, Ulmer J, McCann B and Stollof ER (2009) Planning Complete Streets for an Aging America. Washington, DC: AARP Public Policy Insitute.

Margot-Cattin I, Kuhne N, Kottorp A, Cutchin M, Öhman A and Nygård L (2019) Development of a questionnaire to evaluate out-of-home participation for people with dementia. American Journal of Occupational Therapy 73, 1-10.

Martin D, Long O and Kessler L (2019) Planning for aging in place: incorporating the voice of elders to promote quality of life. Journal of Housing for the Elderly 33, 382-392.

Mattson JW (2011) Aging and mobility in rural and small urban areas: a survey of North Dakota. Journal of Applied Gerontology 30, 700-718.

Mazer B, Laliberté M, Hunt M, Lemoignan J, Gélinas I, Vrkljan B, Naglie G and Marshall S (2016) Ethics of clinical decision-making for older drivers: reporting health-related driving risk. Canadian Journal on Aging/La revue canadienne du vieillissement 35, 69-80.

Metz DH (2000) Mobility of older people and their quality of life. Transport Policy 7, 149-152.

O'Neill D, Walshe E, Romer D and Winston F (2019) Transportation equity, health, and aging: a novel approach to healthy longevity with benefits across the life span (Commentary). National Academy of Medicine Perspectives. Washington, DC: National Academy of Medicine. Available at https://doi.org/ 10.31478/201912a.

Organisation for Economic Co-operation and Development (2011) Ageing and Transport: Mobility Needs and Safety Issues. Paris: Organisation for Economic Co-operation and Development. Available at www.oecd-library.org. 
Papageorgiou N, Marquis R and Dare J (2016) Identifying the enablers and barriers to community participation amongst older adults. British Journal of Occupational Therapy 79, 742-751.

Rantakokko M, Portegijs E, Viljanen A, Iwarsson S and Rantanen T (2013) Life-space mobility and quality of life in community-dwelling older people. Journal of the American Geriatrics Society 61, 1830-1832.

Rapoport MJ, Naglie G, Weegar K, Myers A, Cameron D, Crizzle A, Korner-Bitensky N, Tukko H, Vrkljan B, Bédard M, Porter MM, Mazer B, Gélinas I, Man-Son-Hing M and Marshall S (2013) The relationship between cognitive performance, perceptions of driving comfort and abilities, and selfreported driving restrictions among healthy older drivers. Accident Analysis and Prevention 61, 288-295.

Road Safety Authority (2019) Sláinte agus Tiomáint. Medical Fitness to Drive Guidelines (Group 1 and 2 Drivers), 8th edn, Ballina, Ireland: Road Safety Authority.

Sangrar R, Mun J, Cammarata M, Griffith LE, Letts L and Vrkljan B (2019) Older driver training programs: a systematic review of evidence aimed at improving behind-the-wheel performance. Journal of Safety Research 71, 295-313.

Sixsmith A and Sixsmith J (2008) Ageing in place in the United Kingdom. Ageing International 32, 219-235.

Smith GA, Porter MM, Cull AW, Mazer BL, Myers AM, Naglie G, Bédard M, Tuokko HA, Vrkljan B, Gélinas I, Marshall S and Rapoport MJ (2016) Seasonal and weather effects on older drivers' trip distances. Canadian Journal on Aging/La revue canadienne du vieillissement 35, 59-68.

Stapleton T, Connolly D and O'Neill D (2015) Factors influencing the clinical stratification of suitability to drive after stroke: a qualitative study. Occupational Therapy in Health Care 29, 253-271.

Taylor R (2017) Kielhofner's Model of Human Occupation, 5th Edn. Riverwoods, IL: Wolters Kluwer.

Tuller D, Bangsberg M, Senkungu R, Ware J, Emenyonu N and Weiser C (2010) Transportation costs impede sustained adherence and access to HAART in a clinic population in southwestern Uganda: a qualitative study. AIDS and Behavior 14, 778-784.

Turcotte M (2012) Profile of seniors' transportation habits. Canadian Social Trends 93, 1-16.

Unsworth CA, Wells Y, Browning C, Thomas SA and Kendig H (2007) To continue, modify or relinquish driving: findings from a longitudinal study of healthy ageing. Gerontology 53, 423-431.

Unsworth CA, Baker A, Taitz C, Chan SP, Pallant JF, Russell K, Odell M and Coulson M (2012) Development of a standardised Occupational Therapy Driver Off Road Assessment (OT-DORA) battery to assess older and/or functionally impaired drivers. Australian Occupational Therapy Journal 59, 23-36.

Vaucher P, Choi M, Gélinas I, Harries P, Cattin IM, Mazer B, Van Niekerk L, Patomella A-H, Stapleton T, Swanepoel L, Unsworth CA and Vrkljan B (2017) Development of the International Expert Advisory Panel on Community Health and Transport (I-CHaT) to co-ordinate research on transport mobility. British Journal of Occupational Therapy 81, 245-246.

Vrkljan BH and Polgar JM (2007) Linking occupational participation and occupational identity: an exploratory study of the transition from driving to driving cessation in older adulthood. Journal of Occupational Science 14, 30-39.

Vrkljan BH, Leuty V and Law M (2011) Aging-in-place: exploring the transactional relationship between habits and participation in a community context. OTJR: Occupation, Participation and Health 31, 151-159.

Wiles JL, Leibing A, Guberman N, Reeve J and Allen RE (2012) The meaning of 'aging in place' to older people. The Gerontologist 52, 357-366.

World Health Organization (2015) World Report on Ageing and Health. Geneva: World Health Organization. Available at https:/www.who.int/ageing/publications/world-report-2015/en/.

Yeom HA, Fleury J and Keller C (2008) Risk factors for mobility limitation in community-dwelling older adults: a social ecological perspective. Geriatric Nursing 29, 133-140.

Zeitler E and Buys L (2015) Mobility and out-of-home activities of older people living in suburban environments: 'Because I'm a driver, I don't have a problem'. Ageing \& Society 35, 785-808.

Cite this article: Unsworth C et al (2022). Linking people and activities through community mobility: an international comparison of the mobility patterns of older drivers and non-drivers. Ageing \& Society $\mathbf{4 2}$, 1938-1963. https://doi.org/10.1017/S0144686X20001968 